\title{
VALIDITAS PERANGKAT PEMBELAJARAN BERBASIS INKUIRI PADA MATERI PROTISTA UNTUK MELATIHKAN KETERAMPILAN BERPIKIR KREATIF
}

\section{THE VALIDITY OF LEARNING DEVICES BASED ON INQUIRY IN PROTIST MATERIALS TO TRAIN CREATIVE THINKING SKILLS}

\author{
Rossanita Truelovin Hadi Putri \\ Program Studi Magister Pendidikan IPA Universitas Negeri Surabaya, Indonesia \\ Email: rossanita.18018@mhs.unesa.ac.id
}

Diterima: 30 Juli 2020. Disetujui: 04 Agustus 2020. Dipublikasikan: 30 September 2020

\begin{abstract}
Abstrak: Penelitian ini bertujuan untuk mengetahui validitas perangkat pembelajaran berbasis inkuiri pada materi Protista untuk melatihkan keterampilan berpikir kreatif. Jenis penelitian yang dilaksanakan ialah pre-eksperimen one group pretest and posttest. Perangkat pembelajaran yang dikembangkan mengacu pada model 4D yang terdiri atas tahap define, design, develop, dan disseminate. Perangkat pembelajaran yang dikembangkan ialah RPP, LKPD, BAPD, dan instrumen evaluasi. Validitas perangkat pembelajaran diukur berdasarkan penilaian dosen ahli pendidikan dan dosen ahli materi. Instrumen yang digunakan ialah lembar validasi perangkat pembelajaran. Lembar validasi yang dikembangkan meliputi beberapa kriteria yaitu, kriteria isi, kriteria penyajian dan kriteria bahasa. Hasil penelitian menunjukkan validitas perangkat pembelajaran mendapatkan kategori sangat valid. Berdasarkan hasil penilaian tersebut dapat disimpulkan bahwa perangkat pembelajaran berbasis inkuiri pada materi Protista untuk melatihkan keterampilan berpikir kreatif dinyatakan valid dan layak digunakan pada peserta didik.
\end{abstract}

Kata Kunci: Berpikir Kreatif, Inkuiri, Perangkat Pembelajaran, Protista, Validitas

Abstract: The purpose of this study is to determine the validity of learning devices based on inquiry in protist materials to train creative thinking skills. This research is pre-experiment one group pretest and posttest. This research referred to $4 \mathrm{D}$ model that consisted of Define, Design, and Develop. Development of learning devices is RPP, LKPD, BAPD, and evaluation instrument. The validity of learning devices was measured based on assessment of lecture education and material experts. The instrument used was the validation sheet of learning devices. The validity sheets that were developed included several criteria namely, content criteria, presentation criteria, and language criteria. The results validation of the learning devices the interpretation were very feasible. Consist in these results, it can be concluded that the learning devices based on inquiry of protist material to train creative thinking skill was valid and feasible for use by students.

Keywords: Creative Thinking Skills, Inquiry, Learning Devices, Protist, Validity

\section{PENDAHULUAN}

Pada era globalisasi (era 4.0) ini pendidikan memiliki peran penting bagi perkembangan sumber daya manusia. Pada perkembangan sumber daya abad 21 ini, siswa diharuskan memiliki kemampuan high order thinking (HOT), literasi, PPK, dan 4C (critical thinking, communication, collaboration dan creativity) [1]. Kurikulum 2013 merupakan penyempurnaan kurikulum sebelumnya yang memadukan kompetensi spiritual, sikap sosial, pengetahuan, dan keterampilan [2]. Pembaharuan tersebut diharapkan dapat mengembangkan potensi siswa agar memiliki kemampuan berpikir reflektif untuk menyelesaikan permasalahan lingkungan ataupun sosial.

Pembelajaran biologi merupakan pembelajaran ilmu pengetahuan yang mempelajari tentang makhluk hidup dan hubungannya dengan lingkungan. Mata pelajaran biologi memiliki cakupan pembahasan beraneka ragam makhluk hidup makroskopis (dapat diamati secara langsung) dan mikroskopis (dapat diamati dengan bantuan alat bantu). Salah satu makhluk hidup yang berukuran mikroskopis ialah Protista. Protista merupakan materi biologi yang perlu adanya kegiatan pengamatan [3].

Dalam kurikulum yang berlaku saat ini, Kurikulum 2013 materi Protista tercakup dalam Kompetensi Dasar (KD) 3.6 dan 4.6. Berdasarkan KD tersebut siswa dituntut dapat memahami prinsip klasifikasi untuk penggolongan Protista. Penggolongan protista dapat dilihat berdasarkan ciriciri umum kelas Kingdom Protista. Siswa berpendapat materi protista sulit dipahami karena cakupan materi Protista luas dan dianggap memiliki banyak hafalan nama latin [4]. Materi Protista termasuk materi pelajaran biologi yang abstrak dan sulit dipahami oleh siswa [5]. Pembelajaran aktif dan secara langsung perlu diberikan pada siswa pada saat pembelajaran materi Protista [6]. Observasi terhadap salah satu sekolah di Kota Mojokerto banyak peserta didik yang mengalami kesulitan saat pembelajaran 
tidak diajarkan melalui pengamatan secara langsung [7].

Berdaarkan penelitian-penelitian tersebut adanya perangkat pembelajaran siswa untuk menunjang materi protista belum dikembangkan secara efektif khususnya untuk implementasi Kurikulum 2013 yang berlaku. Perangkat pembelajaran dibutuhkan untuk sebagai penguraian suatu pembelajaran secara rinci agar pembelajaran dapat berlangsung secara maksimal [8]. Pengembangan perangkat pembelajaran yang menunjang kegiatan pengamatan membutuhkan suatu model pembelajaran untuk mempermudah peserta didik dalam belajar. Model pembelajaran inkuiri digunakan oleh guru dalam mengolah pembelajaran yang berpusat pada peserta didik dan memberikan solusi dalam meningkatkan kinerja ilmiah peserta didik. Menurut Pradianti, model pembelajaran inkuiri merupakan proses berpikir yang diawali dengan pengamatan. Inkuiri merupakan suatu proses berpikir yang ditempuh peserta didik untuk menemukan suatu konsep melalui langkah perumusan masalah, pengajuan hipotesis, merencanakan pengujian hipotesis, melakukan pengujian hipotesis melalui eksperimen dan demonstrasi, mencatat data hasil eksperimen, mengolah data, menganalisis data dan membuat kesimpulan [9].

Pada SMA Negeri 1 Mojokerto lembar kegiatan peserta didik yang diberikan masih bersifat informatif, berisi ringkasan materi dan soal-soal latihan. Perangkat yang digunakan bersifat monoton dan belum melatihkan keterampilan berpikir peserta didik [10]. Keterampilan berpikir seharusnya sudah dilatihkan pada peserta didik mengingat era globalisasi sekarang memasuki masa abad 21. Pada perkembangan abad 21 ini, peserta didik diharuskan memiliki kemampuan high order thinking (HOT), literasi, PPK, dan 4C (critical thinking, communication, collaboration dan creativity) [1]. Salah satu keterampilan $4 \mathrm{C}$ ialah creativity (berpikir kreatif) diperlukan untuk menunjang pembelajaran pada Kurikulum 2013 yang berlaku saat ini.

Keterampilan berpikir kreatif peserta didik juga dapat dilatihkan pada peserta didik melalui pemanfaatan Protista bagi kehidupan manusia seharihari. Berpikir kreatif merupakan proses berpikir peserta didik untuk menyelesaikan suatu permasalahan dengan kemampuan melihat suatu masalah dari berbagai sudut pandang dan mampu menghasilkan banyak gagasan. Peserta didik dapat berpikir secara terbuka dan fleksibel dalam menjawab suatu permasalahan yang ada [11]. Carson menyebutkan cara berpikir kreatif dilaksanakan dengan beberapa tahapan, diantaranya mensintesis ide-ide, membangun suatu ide-ide, merencanakan ide-ide, dan menerapkan ide-ide tersebut [12]. Sehingga membentuk suatu gagasan atau produk yang baru, produk yang didapatkan tersebut merupakan suatu kreativitas. Pengembangan perangkat pembelajaran berbasis model inkuiri diharapkan mampu menjadi solusi dalam kegiatan mengklasifikasikan Protista berdasarkan ciri-ciri yang teramati. Perangkat pembelajaran yang dikembangkan diharapkan juga mampu melatihkan keterampilan berpikir kreatif dalam penyelesaian suatu masalah.

Berdasarkan uraian tersebut perangkat pembelajaran perlu divalidasi terlebih dahulu untuk mendapatkan perangkat pembelajaran yang layak dan memenuhi ketercapaian Kompetensi Dasar 3.6 dan 4.6 dengan hasil yang valid. Tujuan penelitian ini yaitu untuk mendeskripsikan validitas perangkat pembelajaran berbasis inkuiri pada materi Protista untuk melatihkan kemampuan berpikir kreatif.

\section{METODE PENELITIAN}

Jenis penelitian ini ialah pre-eksperimen one group pretest and posttest. Pengumpulan bahan dan data penelitian selama pengembangan perangkat pembelajaran dan validasi dilakukan di kampus Universitas Negeri Surabaya. Model pengembangan yang digunakan adalah 4D [13] yang terdiri atas empat tahap, yaitu tahap define (pendefinisian), design (perancangan), develop (pengembangan), dan disseminate (penyebaran). Validasi perangkat pembelajaran di validasi oleh seorang dosen ahli pendidikan dan ahli materi dengan menggunakan instrumen lembar validasi. Penilaian tersebut kemudian dianalisis untuk mengetahui skala penilaian validasi perangkat melalui kriteria penilaian valid tidaknya suatu perangkat pembelajaran [14]. Hasil validasi kemudian dianalisis dengan menggunakan metode analisis deskriptif [15]. Sedangkan untuk mengukur reliabilitas perangkat pembelajaran dihitung dengan rumus percentage agreement [16].

\section{HASIL DAN PEMBAHASAN}

Penelitian ini menghasilkan data berupa hasil validasi dari pengembangan perangkat pembelajaran berbasis inkuiri pada materi Protista untuk melatihkan keterampilan berpikir kreatif. Dalam menghasilkan hasil validasi yang valid dan layak digunakan oleh siswa dalam pembelajaran maka perlu menggunakan model pengembangan yang tepat. Pengembangan perangkat pembelajaran ini menggunakan model pengembangan 4D (define, design, develop dan disseminate).

Pada tahapan define atau pendefisian merupakan langkah awal dalam menganalisis syaratsyarat kriteria pembelajaran. Pada tahapan ini dilakukan dengan menganalisis kurikulum, analisis peserta didik, dan analisis konsep. Analisis perlu dilakukan agar perangkat pembelajaran mendapatkan pengembangan yang sesuai dengan kurikulum yang 
berlaku saat ini. Analisis peserta didik dilakukan untuk mengetahui sejauh mana kemampuan siswa untuk dapat berkembang mengikuti era abad 21 ini. Analisis konsep ditujukan agar konsep yang diajarkan mampu diterima dengan baik oleh siswa.

Tahapan design atau tahapan perancangan merupakan tahapan merancang struktur perangkat pembelajaran pada materi Protista berbasis inkuiri untuk melatihkan keterampilan berpikir kreatif. Langkah awal perancangan ialah menentukan juduljudul dan penulisan dalam membuat perangkat pembelajaran. Sedangkan untuk tahap develop atau tahap pengembangan bertujuan untuk menghasilkan perangkat pembelajaran berbasis inkuiri yang telah direvisi berdasarkan masukan dari ahli pendidikan dan ahli materi. Tahap pengembangan ini berisikan suatu deskripsi tentang kelayakan isi perangkat pembelajaran berbasis inkuiri materi Protista. Langkah pertama dalam tahap ini adalah menghasilkan desain awal perangkat pembelajaran yang dirancang oleh peneliti kemudian ditelaah oleh dosen pembimbing untuk merevisi susunan dan isi perangkat yang kurang tepat. Perbaikan tersebut menghasilkan draft yang selanjutnya akan divalidasi para ahli materi dan pendidikan dengan menggunakan lembar validasi perangkat.

Perangkat pembelajaran yang divalidasi meliputi RPP (Rancangan Pelaksanaan

Tabel 1. Hasil Validasi Perangkat Pembelajaran Berbasis Inkuiri Pada Materi Protista

\begin{tabular}{clccc}
\hline No & $\begin{array}{c}\text { Perangkat } \\
\text { Pembelajaran }\end{array}$ & rerata & $\begin{array}{c}\text { Persentase } \\
(\%)\end{array}$ & Kategori \\
\hline 1 & RPP & 3.68 & 92 & valid \\
\hline 2 & LKPD & 3.8 & 95 & $\begin{array}{c}\text { Sangat } \\
\text { valid }\end{array}$ \\
\hline 3 & BAPD & 3.75 & 93 & $\begin{array}{c}\text { Sangat } \\
\text { valid }\end{array}$ \\
\hline 4 & $\begin{array}{l}\text { Soal } \\
\text { Evaluasi } \\
\text { (Pretest dan } \\
\text { Posttest) }\end{array}$ & 3.7 & 92 & $\begin{array}{c}\text { Sangat } \\
\text { valid }\end{array}$ \\
\hline & Penilaian hasil validasi dan perhitungan
\end{tabular}

reliabilitas pada tabel tersebut didapatkan dari penilaian validasi dosen ahli pendidikan dan dosen ahli materi protista. Data tersebut menunjukkan bahwa perangkat pembelajaran berbasis inkuiri materi protista untuk melatihkan keterampilan berpikir kreatif dinyatakan sangat valid serta reliabel dan layak digunakan oleh siswa dalam pembelajaran materi Protista di sekolah.

Aspek yang dinilai pada perangkat pembelajaran RPP ialah identifikasi RPP, alokasi waktu, indikator pembelajaran, tujuan pembelajaran, materi pembelajaran, metode, sumber belajar, dan media, langkah-langkah pembelajaran, serta penilaian. Hasil rerata RPP yang dihasilkan dari validasi ialah sebesar 3.68 dengan kategori valid.
Pembelajaran), LKPD (Lembar Kegiatan Peserta Didik), BAPD (Buku Ajar Peserta Didik), dan instrument evaluasi berupa pretest dan posttest. Data yang diperoleh berupa hasil penilaian validasi selanjutnya akan dianalisis data oleh peneliti secara deskriptif. Kelayakan perangkat pembelajaran yang dikembangkan ditentukan dari hasil penilaian validasi oleh satu ahli pendidikan dan satu ahli materi dari Jurusan Biologi FMIPA Unesa untuk menilai kebenaran konsep dalam perangkat pembelajaran.

Hasil validasi perangkat pembelajaran menunjukkan keseluruhan hasil dengan kategori sangat valid. Pada hasil validasi RPP menunjukkan persentase sebesar 92\% dengan kategori sangat valid. Pada hasil validasi LKPD menunjukkan persentase sebesar 95\% dengan kategori sangat valid. Pada hasil validasi BAPD menunjukkan persentase sebesar 93\% dengan kategori sangat valid. Sedangkan untuk hasil validasi soal evalusi menunjukkan persentase sebesar 92\% dengan kategori sangat valid. Berikut dijabarkan hasil validasi pada perangkat pembelajaran materi Protista berbasis inkuiri untuk melatihkan keterampilan berpikir kreatif (Tabel 1). Sedangkan untuk hasil percentage of aggrement dapat dilihat pada tabel 2 sebagai berikut.

Tabel 2. Hasil Percentage of Aggrement Perangkat Pembelajaran Berbasis Inkuiri Pada Materi Protista

\begin{tabular}{llll}
\hline No & $\begin{array}{l}\text { Perangkat } \\
\text { Pembelajaran }\end{array}$ & $\begin{array}{l}\text { Percentage of } \\
\text { aggrement }(\%)\end{array}$ & Kategori \\
\hline 1 & RPP & 91.25 & Reliabel \\
\hline 2 & LKPD & 95.3 & Reliabel \\
\hline 3 & BAPD & 94.1 & Reliabel \\
\hline 4 & $\begin{array}{l}\text { Soal } \\
\text { Evaluasi } \\
\text { (Pretest dan } \\
\text { Posttest) }\end{array}$ & 91 & Reliabel \\
\hline & Aspek yang dinilai pada & perangkat
\end{tabular}
pembelajaran LKPD ialah kriteria isi, kriteria penyajian, dan kriteria bahasa. Hasil validasi dari LKPD sebesar 3.8 dan hasil validasi BAPD sebesar 3.75 dengan kategori sangat valid. Pada kriteria isi terdapat empat poin dalam kolom aspek yang divalidasi, terdapat dua poin yang memiliki nilai kategori valid. Aspek kebenaran konsep memiliki nilai dengan kategori sangat valid, aspek ini memiliki peran yang penting dalam pembelajaran. Apabila konsep yang diajarkan oleh guru mengalami kesalahan, maka peserta didik berpeluang tinggi mengalami suatu miskonsepsi materi Kingdom Protists. Aspek kesesuaian LKPD dengan pembelajaran berbasis inkuiri memiliki nilai kategori valid. Pembelajaran inkuiri merupakan proses 
dimana peserta didik menemukan atau membuat hipotesis dalam suatu permasalahan dan peserta didik dapat mencari solusi penyelesaian untuk memecahkan suatu masalah [17].

Aspek kriteria isi LKPD untuk melatihkan keterampilan berpikir kreatif memiliki nilai kategori valid. Berpikir kreatif merupakan salah satu tagihan keterampilan dalam pembelajaran abad 21 ini. Pembelajaran yang melatihkan keterampilan berpikir kreatif dibutuhkan untuk menunjang kepribadian peserta didik berpikir out to the box. Saat seseorang berpikir kreatif, dia otomatis berpikir kritis karena memilah segenap pengetahuan dan kemampuan yang telah dimilikinya, mengkritisi sebelum menerapkan dalam menyelesaikan masalah [18]. Menurut Cohean \& Swerdlik [19] berpikir kreatif memiliki empat dimensi yaitu, kefasihan (fluency), fleksibilitas (flexibility), orisinalitas (originality), elaborasi (elaboration).

Kriteria penyajian pada keseluruhan hasil penilaian yang didapatkan dari validator memiliki kategori sangat valid. Pada kriteria penyajian terdapat beberapa poin yang keseluruhan poin menyebutkan tentang suatu struktur dan desain dari LKPD dan BAPD. Perangkat pembelajaran LKPD dan BAPD sendiri harus memiliki suatu nilai yang eye catching yang apabila dibaca dapat membuat orang tertarik saat membacanya. Aspek tampilan LKPD dan BAPD juga termasuk katergori sangat valid, dilihat dari tampilan LKPD dan BAPD yang tidak berlebihan. Pemilihan gambar dan menggunakan variasi warna dengan baik serta mencantumkan hal-hal baru dapat menarik perhatian peserta didik untuk belajar. LKPD dan BAPD sangat penting dalam pembelajaran, karena mampu memudahkan guru dalam melaksanakan pembelajaran. LKPD dan BAPD juga mampu sebagai alternatif sumber belajar dan bahan ajar yang sudah disesuaikan dengan kebutuhan, karakteristik dan lingkungan peserta didik serta mengacu pada kompetensi dasar yang harus dicapai oleh peserta didik sehingga peserta didik terlibat aktif dalam kegiatan pembelajaran [20].

Kriteria yang terakhir ialah kriteria bahasa, aspek kebahasaan pada LKPD dan BAPD harus menggunakan penulisan Bahasa Indonesia yang baik dan benar sesuai dengan EYD, dan bahasa yang digunakan sudah sesuai dengan kemampuan berpikir peserta didik. Aspek pertama dari poin kriteria bahasa ialah penulisan bahasa mudah dipahami oleh peserta didik mendapatkan kategori sangat valid. Penulisan bahasa yang digunakan pada LKPD dan BAPD sudah sesuai dengan batasan umur peserta didik mulai 15 tahun hingga dewasa. Peserta didik yang berumur diatas 15 tahun sudah mampu berpikir secara abstrak untuk membayangkan sesuatu dipikirannya [21]. Aspek kedua ialah penggunaan kata baku sesuai, pada kedua valiator memberikan penilaian yang berbeda. Salah satu validator memberikan penilaian tidak pada aspek ini, dengan pemberian keterangan terdapat salah satu kata yang dirasa kurang baku. Kata baku dapat diartikan dengan kata yang sudah benar dari segi aturan maupun ejaan kaidah Bahasa Indonesia. Kaidah Bahasa Indonesia ini umumnya dikenal sebagai Ejaan Yang Disempurnakan (EYD) atau tata bahasa baku. Sumber valid untuk rujukan berbagai macam bahasa baku ialah melalui Kamus Besar Bahasa Indonesia (KBBI). Aspek terakhir pada kriteria bahasa ialah menggunakan kalimat yang komunikatif, aspek ini mendapatkan kategori sangat valid. Kalimat dapat dikatakan komunikatif apabila memenuhi beberapa persyaratan yaitu, sesuai dengan kaidah Bahasa Indonesia, sesuai dengan nalar, dan sesuai dengan pesan yang dimaksut oleh pembicara.

Sedangkan untuk validasi soal evaluasi salah satu dosen memberikan masukan pada penulisan soal yang masih kurang dengan ranah kognitif siswa. Ranah kognitif yang seharusnya digunakan pada perangkat pembelajaran ini ialah C6. Siswa mampu membuat sesuatu yang baru berupa produk dari kemampuan proses berpikir siswa.

Dalam penelitian ini, validitas suatu perangkat pembelajaran dapat dikatakan valid apabila mendapatkan skor rata-rata diatas 2.6. Pada penelitian pengembangan ini mendapatkan skor ratarata >3.68 kategori valid dan menghasilkan presentase $>92 \%$. Hasil presentase tersebut dikategorikan sangat tinggi dibandingkan batas minimal dari valid ialah sebesar $75 \%$. Perangkat pembelajaran berbasis inkuiri pada materi Protista untuk melatihkan keterampilan berpikir kreatif ini memiliki validiatas sangat baik dan dapat dijadikan perangkat pembelajaran di sekolah yang bisa digunakan guru untuk mengajar dikelas.

\section{KESIMPULAN}

Berdasarkan hasil penelitian dan pembahasan tersebut, dapat disimpulkan bahwa persentase validitas perangkat pembelajaran RPP, LKPD, BAPD dan soal evaluasi berbasis inkuiri pada materi protista untuk melatihkan keterampilan berpikir kreatif peserta didik dinyatakan dengan kategori sangat valid, sehingga layak untuk diterapkan dalam pembelajaran di sekolah.

\section{DAFTAR PUSTAKA}

[1] Kemendikbud. 2017. Panduan Implementasi Kecakapan Abad 21 Kurikulum 2013 di Sekolah Menengah Atas. Jakarta: Kementerian Pendidikan dan Kebudayaan Republik Indonesia.

[2] Permendikbud. 2016. Lampiran Peraturan Menteri Pendidikan dan Kebudayaan Republik Indonesia Nomor 20 tahun 2016 Tentang Standar Kompetensi Lulusan Pendidikan Dasar 
dan Menengah. Jakarta: Kementerian Pendidikan dan Kebudayaan Republik Indonesia.

[3] Bode, C., Criss, M., Ising, A., McCue, S., Ralph, S., Sharp, S., Smith, V., Sturm, B. (2014). Pond Power. National Science Teacher Association, 81 (02), 43-49.

[4] Mukaromah, E., Bintari, Siti H., dan Mubarok, I. (2012). Hasil Belajar Siswa Pada Materi Protista Akibat Penerapan Model Learning Cycle. Unnes Journal of Biology Education, 1(2), 182-189.

[5] Febriana, D., Sajidan, dan Prayitno, B. A. (2015). Pengembangan Multimedia Interaktif Berbasis Group Discovery Learning (GDL) Pada Materi Protista Kelas X SMA Negeri Karangpandan. Jurnal Inkuiri, 4(2), 97-108.

[6] Widyaningrum, D. A. dan Wahyuni, L. (2020). Analisis Pengembangan Modul Pembelajaran Berbasis Reciprocal Teaching Pair Share. PEDAGOGIA: Jurnal Pendidikan, 9 (1), 99102.

[7] Wahyuningtyas, Hanum, dan Isnawati. (2019). Validitas dan Keefektifan Lembar Kerja Peserta Didik Berbasis Literasi Sains Pada Materi Fungi Untuk Melatihkan Berpikir Tingkat Tinggi Peserta didik Kelas X SMA. BioEdu, 8(2), 145-151.

[8] Kusumaningrum, S. dan Djukri, D. (2016). Pengembangan Perangkat Pembelajaran Model Project Based Learning (PjBL) untuk Meningkatkan Keterampilan Proses Sains dan Kreativitas. Jurnal Inovasi Pendidikan IPA, 2(2), 241-251.

[9] Pradianti, D., Wasis, dan Agustini, R. (2015). Pengembangan Perangkat Pembelajaran Fisika Model Inkuiri Terbimbing untuk Melatihkan Kinerja Ilmiah Peserta didik. Pendidikan Sains Pascasarjana Universitas Negeri Surabaya, 4(2), 673-680.

[10] Saputra, S.A., dan Kuntjoro, S. (2019). Keefektifan Lembar Kegiatan Peserta Didik Berbasis Problem Based Learning Pada Materi Perubahan Lingkungan untuk Melatihkan Keterampilan Berpikir Kritis. BioEdu, 8(2), 291-297.

[11] Asmara, R., Susantini, E., dan Rahayu, Y.S. (2015). Pengembangan Perangkat Pembelajaran Biologi Berorientasi Pendekatan TASC (Thinking Actively in Social Conteks) untuk Melatihkan Keterampilan Berpikir Kreatif Peserta didik. Pendidikan Sains Pascasarjana Universitas Negeri Surabaya, 5(1), 885-890.

[12] Carson, S. 2015. Targeting Critical Thinking Skills in a First Year Undergraduate Research Course. J.Microbiol. Biol.Educ, 16, 148-156.

[13] Thiagarajan dan Semmel. 1974. Instructional Development for Training Teachers of
Exceptional Children. Indiana: Indiana University Bloomington.

[14] Ratumanan, G.T. dan Laurens. 2011. Evaluasi Hasil Belajar Tingkat Satuan Pendidikan. Surabaya: Unesa University Press.

[15] Arikunto, S. 2010. Prosedur Penelitian Suatu Pendekatan Praktek. Jakarta: Rineka Cipta.

[16] Borich, G. D. 1994. Observation Skills for Effective Teaching. New York: Macmillan Publishing Company.

[17] Pedaste, Margus, Maeors M., Leijen, A. \& Sarapuu. (2012). Improving Students' Inquiry Skill Through Reflection and Self-regulation Scaffolds. Technology, Instruction, Cognition and Learning, 9 (1), 81-95.

[18] Prayitno, Edi. (2016). Pengembangan Berpikir Divergen dan Kritis Melalui Soal Terbuka. Jurnal Unimus, 3(01).

[19] Cohean, R. J. dan Swerdlik, M. E. 2010. Psychology Testing and Assessment 7th edition. New York: McGraw-Hill Companies, Inc.

[20] Prastowo, Andi. 2015. Panduan Kreatif Membuat Bahan Ajar Inovatif. Yogyakarta: Diva Press.

[21] Piaget, J dan Inholder. 2010. Psikologi Anak (Alih Bahasa: Miftahul Jannah). Yogyakarta: Pustaka Pelajar. 